\title{
О синдроме Мейгса вследствие экстракорпорального оплодотворения
}

1 - кафедра фтизиатрии и пульмонологии Харьковской медицинской академии последипломного образования: 61037, Харьков, Московский пр-т, 197; 2 - Городская клиническая больница № 13: 61035, г. Харьков, пр-т Гагарина, 137

\section{V.S.Krutko, E.M.Khodosh, P.I.Poteiko \\ About the Meigs' syndrome as a consequence of extracorporeal fertilization}

Key words: Meigs' syndrome, ascite, pleural effusion, extracorporeal fertilization.

Ключевые слова: синдром Мейгса, асцит, плеврит, экстракорпоральное оплодотворение.

В 1954 г. J.V.Meigs описал синдром (называемый также синдромом Мейгса-Салмона, Демонса-Мейгса), характеризующийся образованием асцита и плеврального выпота у больных с доброкачественной солидной опухолью яичника [1]. В дальнейшем синдром Мейгса стали рассматривать как возникновение асцита, гидроторакса и явлений общего истощения при доброкачественной опухоли яичника и матки. Затем эту патологию стали описывать у больных со злокачественной опухолью яичников, но без признаков метастазирования. Р.У.Лайт предложил относить к синдрому Мейгса все новообразования тазовой области, сопровождающиеся асцитом и плевральным выпотом, если хирургическая экстирпация опухоли обеспечивает рассасывание асцита и плеврального выпота [2]. Вариантом данного заболевания считались те случаи, когда клиника была похожа на синдром Мейгса-Салмона, но яичники подвергались дегенеративным изменениям без опухоли. Также известно, что обширный отек яичников без опухолевых изменений вызывает гидроторакс и асцит. Образование асцита и плеврального выпота как отдельных осложнений стали рассматривать и при синдроме гиперстимуляции яичников (СГЯ) [3]. Несмотря на накопление знаний об этой патологии, патогенез синдрома Мейгса окончательно не изучен.

Наиболее часто синдром Мейгса возникает у больных с фибромой яичников, на 2-м по распространенности месте - киста яичников, на 3-м - лейомиома матки. Плевральный выпот возникает у $3 \%$ пациенток с овариальными опухолями, достигающими $>6$ см в диаметре. В $70 \%$ случаев плевральный выпот правосторонний, в $10 \%$ - левосторонний и в $20 \%-2$-сторонний [2, 4-6].

Хотя плевральный выпот у больных с синдромом Мейгса часто считают транссудатом, иногда содержание в нем белка превышает 35 г/л, что свидетельствует об экссудате; в отдельных случаях плевральный выпот может быть геморрагическим [2, 4-6]. Образование плеврального транссудата или экссудата объясняется транспортом выпота из брюшной по- лости в плевральную через лимфатическую систему диафрагмы [1]. После хирургического удаления первичной опухоли наблюдается быстрое рассасывание асцита и плеврального выпота (как правило, через 2 нед.) [4-6].

В приведенном здесь клиническом наблюдении асцит и плевральный выпот возникли в период экстракорпорального оплодотворения, технология которого состоит из нескольких этапов: 1) стимуляция яичников препаратами-индукторами (хумегон, метродин и др.) для созревания нескольких фолликулов; 2) пункция фолликулов и забор яйцеклеток; 3) оплодотворение яйцеклеток и культивирование эмбрионов; 4) перенос полученных эмбрионов в полость матки. В отдельных случаях данной методики наблюдается СГЯ как чрезмерная реакция яичников на применение и избыток препаратов-индукторов (гонадотропы и агонисты гонадолиберинов). В этих случаях концентрация стероидных гормонов возрастает в 20-25 раз, что приводит, с одной стороны к увеличению проницаемости сосудистой стенки, а с другой - к нарушению водно-электролитного баланса. В то же время вводимая комбинация препаратов необходима для стимуляции производства нескольких яйцеклеток и обеспечения гарантии их хорошего качества. Действие этих препаратов обычно контролируется с помощью трансвагинальной эхолокации и периодических анализов крови и мочи для уточнения уровня стероидных гормонов. СГЯ обычно начинается с момента подсадки эмбриона в тело матки. В результате может развиться резкий и значительный отек яичника вплоть до его разрыва с кровотечением из него или влагалищного сосуда, возникновением асцита, плеврита и даже перикардита.

Приводим клиническое наблюдение.

Больная Б. 27 лет в связи с бесплодием поступила в клинику центра планирования семьи и репродукции человека, где ей 03.02.09, на 2-й день менструального цикла, начата стимуляция овуляции под ежедневным трансвагинальным ультразвуковым контролем для измерения размеров фолликулов и их количества. 


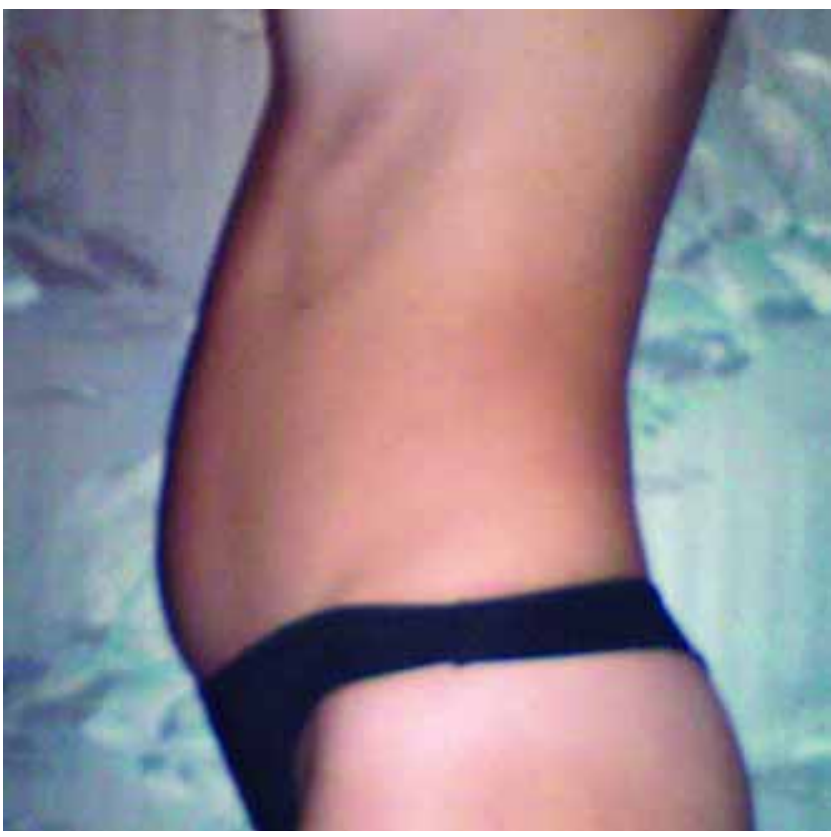

Рис. 1. Больная Б. Увеличенный в объеме живот - асцит

Цель - добиться размеров фолликулов $\leq 20$ мм. Превышение их размеров и количества (> 30) является сигналом для пункции и отсасывания фолликулов, причем при этом яичник не должен быть травмирован. Известно, что в данном клиническом наблюдении проводились пунктирование и эвакуация фолликулов, а также перенос эмбриона в полость матки. Трудно сказать, в связи с чем развился синдром Мейгса (травма яичника при пункции? избыток индукторов? СГЯ с разрывом яичника или без него?), но в последующие дни состояние больной ухудшилось: появилась сильная боль в правой паховой области, повысилась температура тела до $38^{\circ} \mathrm{C}$, заметно увеличился в объеме живот (окружность живота - до 90 см при исходных 60 см; рис. 1). При трансвагинальной эхографии описаны лишь значительный отек правого яичника и наличие жидкости в брюшной полости.

Больной было проведено лечение диферелином, фостимоном, прогестероном и метипредом. Боль в правой паховой области исчезла. Однако состояние оставалось средней тяжести, появились одышка и слабость. На рентгенограмме органов грудной клетки (прямой и боковой) от 16.02 .09 обнаружен правосторонний плевральный выпот (рис. 2).
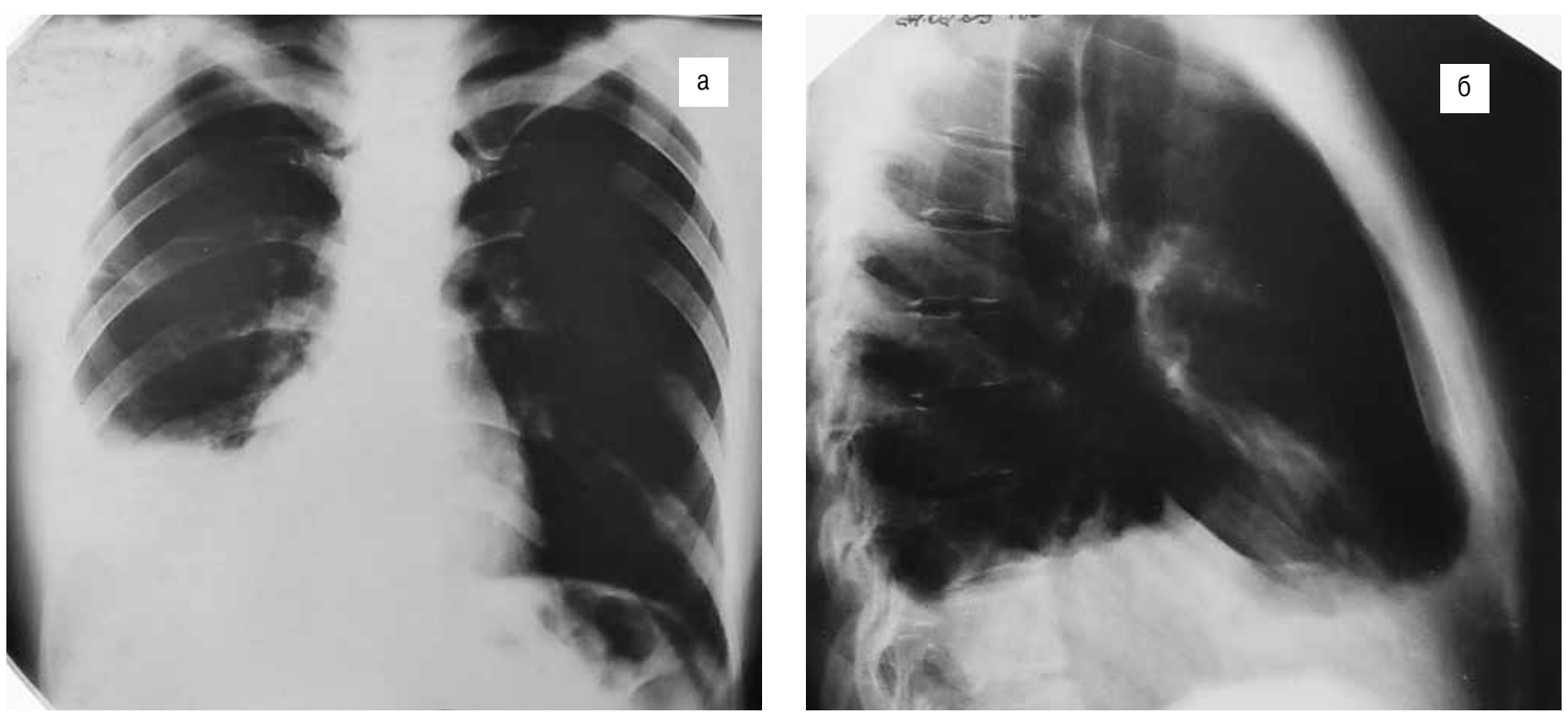

Рис. 2. Рентгенограммы больной Б. в прямой (а) и боковой (б) проекциях от 16.02 .09 - выпот в правой плевральной полости от IV ребра книзу.
Для дальнейшего лечения пациентка была переведена в пульмонологическое отделение. При поступлении состояние средней тяжести. Кожа и видимые слизистые умеренно бледны. Частота дыхания - 20 мин $^{-1}$; частота сердечных сокращений - 96 уд./мин; артериальное давление - 120 / 90 мм рт. ст. Аускультативно над легкими слева дыхание было жестким, справа - ослабленным, перкуторно справа в нижних отделах определялось притупление. Язык влажный, чистый. Живот участвует в акте дыхания, несколько увеличен в размерах за счет свободной жидкости, при пальпации мягкий, умеренно болезненен в нижнем отделе справа. Печень - у края реберной дуги. Селезенка не пальпируется.

Клинический анализ крови от 17.02.09: эритроциты $-3,7 \times$ $10^{12} /$ л; гемоглобин - 119 г/л; лейкоциты $-8,8 \times 10^{9} /$ л; эозинофинейтрофилы - $68 \%$; лимфоциты - $26 \%$; моноциты - $3 \%$; СОЭ 40 мм/ч. Клинический анализ мочи от 17.02.09: удельный вес1028 г/л; белок - 0,033 г/л; лейкоциты - 15-20 в поле зрения; эритроциты - неизмененные, 10-15 в поле зрения.

Трижды проводилась плевральная пункция с аспирацией 1 300, 400 и 100 мл соломенно-желтого выпота, который оказался экссудатом. Анализ плеврального выпота: удельный вес - 1,015; белок - 40,5 г/л; реакция Ривальта - положительная; эритроциты $30-40$ в поле зрения; лейкоциты - 40-50 в поле зрения; лимфоциты $-90 \%$; нейтрофилы $-10 \%$; мезотелий - скоплениями и по отдельности - в большом количестве, отдельные клетки - в состоянии пролиферации; опухолевые клетки и микобактерии туберкулеза не обнаружены.

Назначено лечение: Локсоф, Неогемодез, Кетанов, 5\%-ная глюкоза, витамин С.

Клинический анализ крови в динамике от 12.03.09: эритроциты $-3,9 \times 10^{12} /$ л; гемоглобин - 124 г/л; лейкоциты $-7,0 \times 10^{9} /$ л; эозинофилы - $2 \%$; палочкоядерные нейтрофилы - $3 \%$; сегментоядерные нейтрофилы - $54 \%$; лимфоциты - $39 \%$; моноциты $2 \%$; СОЭ - 18 мм/ч. Клинический анализ мочи от 13.02.09: удельный вес - 1015 г/л; белок и сахар отсутствуют; лейкоциты - 2-4 в поле зрения

Компьютерная томография (КТ) нижней половины грудной клетки и органов брюшной полости проведена 10.03.09: легкие и плевра на исследуемом уровне - без очаговых и инфильтративных изменений. Выпот в плевральной и брюшной полостях не визуализируется. Других видимых органических изменений в органах брюшной полости не выявлено (рис. 3). В ходе трансвагинальной эхографии от 13.03 .09 патологии со стороны гениталий не обнаружено. Клинический диагноз - синдром Мейгса вследствие синдрома гиперстимуляции яичников при экстракорпоральном оплодотворении.

Таким образом, в результате возникшего СГЯ возник острый воспалительный и чрезмерный отек правого яичника с послелы - $1 \%$; палочкоядерные нейтрофилы - $2 \%$; сегментоядерные 


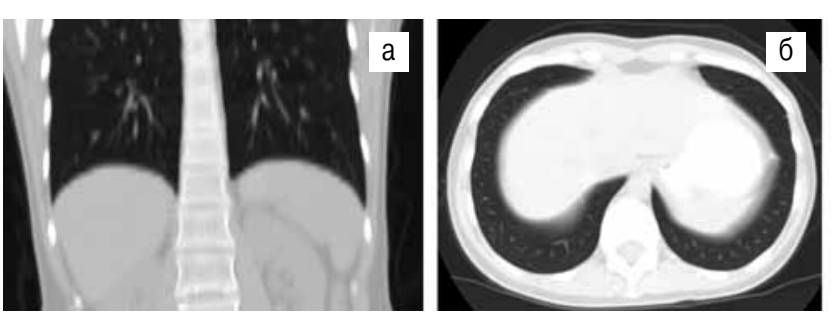

дующим образованием асцита и правостороннего плеврального выпота. Воспалительный процесс разрешился, возможно, в результате консервативной терапии, а вероятно, и в результате дренирования яичника, вследствие чего нормализовались его размеры, секреторная и метаболическая функции. В итоге стабильно отсутствовали асцит и плевральный выпот. Было констатировано выздоровление.

Семиотика заболевания, последовательность образования выпотов (от брюшной полости к плевральной), результаты клинико-инструментальных методов обследования и их динамика, а также исход соответствуют клинической картине синдрома Мейгса [7]. Поэтому можно считать, что известные осложнения экстракорпорального оплодотворения удалось подкрепить и уточнить в контексте уже сложившегося представления о синдроме Мейгса, т. е. его неоперативного варианта, и, таким образом, нозологически расширить это клиническое понятие.

\section{Литература}

1. Meigs J.V. Fibroma of the ovary with ascites and hydrothorax - Meigs' syndrome. Am. J. Obstetr. Gynecol. 1954; 67 (5): 962-985.

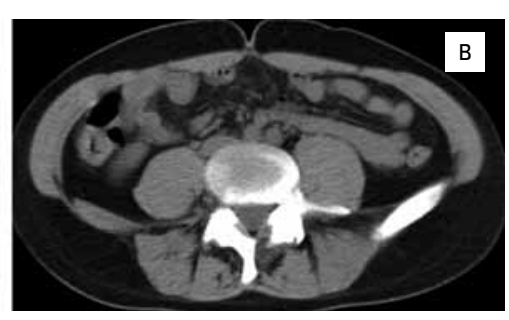

Рис. 3. КТ больной Б. от 10.03.09: а - КТ-реформация во фронтальной плоскости; б - базальных отделов легких; в - брюшной полости. Выпот в плевральной и брюшной полостях не визуализируется

2. Лайт Р.У. Болезни плевры: Пер. с англ. М.: Медицина; 1986. 267-269.

3. Овчаренко С.И., Сон Е.А. Плевральный выпот: вопросы диагностики. Consilium Medicum 2009; 1: 36-38.

4. Moran-Mendoza A., Alvarado-Luna G., Calderillo-Ruiz G. et al. Elevated CA-125 level associated with Meigs' syndrome: case report and review of the literature. Int. J. Gynecol. Cancer 2006; 16 (suppl. 1): 315-318.

5. Lanitis S., Sivakumar S., Behranwala K. et al. A case of Meigs' syndrome mimicking metastatic breast carcinoma. Wld J. Surg. Oncol. 2009; 7: 10.

6. Lurie S. Meigs' syndrome: the history of the eponym. Eur. J. Obstetr. Gynecol. Reprod. Biol. 2000; 92 (2): 199-204.

7. Крутько В.С., Потейко П.И., Бызов В.В., Ходош Э.М. Синдром Мейгса как осложнение овуляционного стимулирования при экстракорпоральном оплодотворении. Новости медицины и фармации 2009; 8-9: 23-24.

\section{Информация об авторах}

Крутько Валерий Семенович - д. м. н., проф., зав. кафедрой фтизиатрии и пульмонологии ХМАПО; тел. / факс: (8057) 738-71-87; e-mail: kfp1930@ukr.net

Ходош Эдуард Михайлович - к. м. н., доцент кафедры фтизиатрии и пульмонологии ХМАПО, зав. 1-м пульмонологическим отделением Городской клинической больницы № 13; тел.: (8057) 721-26-81; e-mail: e_khodosh@mail.ru

Потейко Петр Иванович - к. м. н., доцент кафедры фтизиатрии и пульмонологии ХМАПО; тел. / Факс: (8057) 738-71-87; e-mail: ppi@ukr.net

Поступила 21.07.09 () Коллектив авторов, 2010

УдК 618.11-006.327-06:[616.381+617.54]-003.217 